\title{
Recent advances in depression across the generations
}

\author{
MYRNA M. WEISSMAN
}

\begin{abstract}
This Editorial presents recent research on the transmission of depression across three generations and discusses the implications for improving detection, treatment and prevention and for identifying important subgroups for biological studies. It reports a case-control study of three generations at high or low risk for major depression. The first two generations were followed longitudinally for 20 years and were assessed blind to the clinical status of the other generations. Depression is highly familial across three generations. Over $60 \%$ of grandchildren (average age 12 yrs.) with two generations affected with depression already have some psychopathology. Anxiety disorders are usually the first presentation before puberty with an increase in depression in adolescents, especially among girls. New opportunities for early detection and treatment exist. Families with three generations affected with depression present a potentially important group for biological, genetic and neuroimaging studies.
\end{abstract}

\section{INTRODUCTION}

Depression is a major health problem and a call for public health programs aimed at improving recognition, treatment and reducing consequences has been eloquently described in the editorial by Dr. Paykel. I would like to present some recent research that points to possible areas of early detection and intervention.

I will present a study of three generations at high and low risk for depression. The first two generations have been followed for over 20 years and the second generation from childhood and/or adolescence to adulthood. The third generation, the grandchildren, has been recently assessed. The cumulative results of this study show the emerging integration of epidemiologic studies with modern methods from neuroscience and point to the direction of prevention.

Address for correspondence: Professor M.M. Weissman, College of Physicians and Surgeons, Columbia University, Department of Clinical and Genetic Epidemiology, New York State Psychiatric Institute, 1051 Riverside Drive, Unit 24, New York, NY 10034 (USA).

Fax: 212-568-3534

E-mail: mmw3@columbia.edu

Declaration of Interest: This research was funded by RO1 MH 036197 from the National Institute of Mental Health. Dr. Weissman has received investigator initiated research award and served on the scientific advisory board of drug companies with interests in antidepressants. A portion of this material can be found in Weissman et al. Families at High and Low Risk for Depression: A 3-Generation Study. Archives of General Psychiatry 2005. Permission obtained.

\section{BACKGROUND FOR THE STUDY}

The familial nature of major depression (MDD) has been documented in numerous family studies (Weissman et al., 1987; Gershon et al., 1982; Klein et al., 2001) with a two-fold increase of MDD in the first degree relatives of depressed patients as compared to controls. Retrospective data on the onset and course of MDD from family studies show that early age of onset and recurrence are associated with increased familial clustering of MDD (Wickramaratne et al., 2000; Kaufman et al., 2001). These findings are supported by studies of offspring of parents with MDD, where there is over a threefold increased risk among child and adolescent offspring (Downey \& Coyne, 1990; Kovacs et al., 1997; Hammen et al., 1990; Warner et al., 1999; Williamson et al., 2004). None of the published high risk studies previously had gone beyond two generations. Few have a longitudinal design (Hammen et al., 1990; Williamson et al., 2004; Orvaschel et al., 1988; Lewinsohn et al., 2003). We have followed the offspring of depressed and nondepressed parents (generation 1) for about 20 years. The offspring (generation 2) are now adults and also have children of their own (generation 3), the grandchildren of the original cohort. Previously, we published results from a 10-year follow-up of the first two generations (Weissman et al., 1997) and preliminary results on a sample of grandchildren (Warner et al., 1999). We showed that grandchildren in families with multiple generations of MDD were at high risk for psychopathology. At that time, the second generation had not fully passed through the age of risk for MDD (Weissman et al., 1997) and 
there were only 90 grandchildren (Warner et al., 1999). In the last follow-up we reported the results from the first two generations and 161 grandchildren.

We hypothesized that multigenerational MDD (i.e., presence of MDD in both grandparent and parent) would be associated with significantly greater risk of mood and anxiety disorders among grandchildren. A number of the grandchildren were prepubertal and our previous analysis of the first two generations, as well as results of other studies (Pine et al., 1998; Beidel \& Turner, 1997; Hettema et al., 2003; Wittchen et al., 2000), have shown that anxiety disorders usually preceded depression in the sequence of onset. Therefore, we expected that the young grandchildren in the high risk groups, like their ancestors, would have high risk of anxiety disorders.

\section{FINDINGS}

The major findings of this three generation study were the moderating effects of grandparent depression on the association between parent depression and grandchild diagnoses; the importance of impairment in depression criteria; the stability of the finding that anxiety disorders are an early sign of psychopathology in children from depressed families. Nearly $60 \%$ of the grandchildren (mean age 12 years) with two generations of depression already had some psychiatric disorders. The increase in anxiety disorders in the grandchildren from high risk grandparents was consistent with the findings from their parents, when they were the same age as the grandchildren (Warner et al., 1999; Wickramaratne \& Weissman, 1998). Anxiety disorders in children as the precursor of later depression in adolescence and young adulthood has been shown in our data on the previous generations, in community studies of children (Pine et al., 1998; Kessler et al., 2001) and of adults (Hettema et al., 2000) and in other high risk studies (Beidel \& Turner, 1997). Taken together these findings suggest that anxiety can be viewed as an agedependent expression of the same underlying disorder. A large number of the grandchildren in our study were prepubertal. If anxiety is a precursor of depression, we expect that the risk for depression will begin to increase in adolescence in the high risk grandchildren who are showing prepubertal anxiety.

Non-familial MDD (i.e. depression in the second generation, with non-depressed grandparents); was of low prevalence and transmitted impairment but not specific psychiatric disorders to the grandchildren. We found, previously, that offspring from low risk families who become depressed have a later age of onset and their MDD was associated with family risk factors (Nomura $e t$ $a l ., 2002$ ). Inclusion of parents only with moderate to severe depression, as measured by impairment, significantly increased the number of grandchildren with mood disorders in the high risk group. Impairment added to MDD criteria has been shown to increase familial aggregation in twin (Foley et al., 2003) and family studies (Gershon et al., 1986). Our findings confirm that impairment should be considered an additional criterion for MDD when looking at familial transmission. Impairment in a depressed parent may decrease the age of onset of MDD in the next generation, and the offspring of parents with less impairing MDD may have a later age of onset of MDD.

\section{IMPLICATIONS}

Our findings have clinical and research implications. Obtaining family history of depression, its severity and impairment in previous generations should help identify persons at high risk for psychopathology at a young age. There are relatively simple family history screens, available to obtain this information (Weissman et al., 2000). We have shown previously that the offspring of depressed mothers identified and treated in primary care had similar high rates of psychopathology in their children (Weissman et al., 2005). This suggests that family history should be screened in primary care when the patient has depression.

Children with two generations of MDD should be identified and considered for treatment if they develop anxiety disorders. A study has yet to be done to test whether treating anxiety disorders or possibly disruptive disorders in prepubertal youth from high risk families will delay or even prevent the onset of MDD later. Delaying the onset of MDD in adolescence when choices about education, work and life partners are being formed could have an impact on reducing the disability of MDD. The high rate and early onset of illness in the grandchildren from two generations of depression suggests that this group as contrasted with the low risk groups could provide promising contrasts for neuroimaging, genetic and other biologic studies. In collaboration with Dr. Bradley Peterson, we are now conducting functional and anatomical magnetic resonance imaging (MRI) studies of the three generations to develop hypotheses about brain endophenotypes. Our findings, if replicated, also point out the heterogeneity of major depression and the potential confounding in biological 
studies including depressed patients without obtaining a detailed family history. Our findings also suggest that non-impairing MDD may be a phenocopy and that impairment criteria should continue to be used in genetic studies of depression.

Caspi et al. (2003) has shown that a functional polymorphism in the promoter region of the serotonin transporter gene moderated the effect of life events on developing depression. They showed that the effects of the genes are conditional on exposure to environmental risks. Our findings suggest another point of heterogeneity in depression. The development of depression in a young person may be conditional on both the parent and grandparent having a moderate to severe depression. These effects may be independent of environmental confounders. Whether these generations also carry the functional polymorphism is an interesting unanswered question. Since parents may provide both high risk genes and a high risk rearing environment, disentangling psychosocial and biological factors mediating the transmission of risk across generations is a challenge.

Finally, what about treatment? Our study and others have shown that depression begins early, often in adolescence. The treatment of depression in adolescents has become controversial because of recent findings of a possible increase in suicidal thoughts in adolescents receiving antidepressants. There is now reasonable evidence for the efficacy of interpersonal psychotherapy and cognitive behavioral therapy without medication for the treatment of depressed adolescents (Mufson et al., 2004; Brent et al., 1997).

One obstacle to the increased use of evidence based psychotherapy in clinical practice is the large gap between research evidence and clinical practice. This gap is due to the relative newness of these treatments and the reluctance of training programs in psychiatry to change their curricula to include more evidence based treatments.

Since the efficacy of medication and/or psychotherapy for the treatment of depressed adults is well established a reasonable question is whether the effective treatment of a depressed parent can help reduce or delay the symptoms in the offspring. We are currently testing this hypothesis. We are also collecting blood for DNA to enter these families into genetic studies. Well characterized subjects in the epidemiologic studies are a valuable resource for modern genetic and imaging studies and for providing clues to risk which can lead to a better understanding of the disorders and better treatments.

\section{REFERENCES}

Beidel D. \& Turner S. (1997). At risk for anxiety, I: psychopathology in the offspring of anxious parents: a direct interview study. Journal of the American Academy of Child and Adolescent Psychiatry 36, 918-924.

Brent D.A., Holder D., Kolko D., Birmaher B., Baugher M., Roth C., Iyengar S. \& Johnson B.A. (1997). A clinical psychotherapy for adolescent depression comparing cognitive, family, and supportive therapy. Archives of General Psychiatry 54, 877-885.

Caspi A., Sudgen K., Moffitt T.E., Taylor A., Craig I.W., Harrington H., McClay J., Mill J., Martin J., Braithwaite A. \& Poulton R. (2003). Influence of life stress on depression: Moderation by a polymorphism in the 5-HTT gene. Science 301, 386-389.

Downey G. \& Coyne J.C. (1990). Children of depressed parents: An integrative review. Psychological Bulletin 108(1), 50-76.

Foley D.L., Neale M.C., Gardner C.O., Pickles A. \& Kendler K.S (2003). Major depression and associated impairment: Same or different genetic and environmental risk factors? American Journal of Psychiatry 160, 2128-2122.

Gershon E.S., Hamovit J.A., Guroff J.J., Dibble E., Leckman J.F., Sceery W., Targum S.D., Nurnberger Jr. J.I., Goldin L.R. \& Bunney Jr. W.E. (1982). A family study of schizoaffective bipolar I, bipolar II, unipolar, and normal control probands. Archives of General Psychiatry 39(10), 1157-1167.

Gershon E.S., Weissman M.M., Guroff J.J., Prusoff B.A. \& Leckman J.F. (1986).Validation of criteria for major depression through controlled family study. Journal of Affective Disorders 11, 125-131.

Hammen C., Burge D., Burney E. \& Adrien C. (1990). Longitudinal study of diagnoses in children of women with unipolar and bipolar affective disorder. Archives of General Psychiatry 47, 1112 1117.

Hettema J.M., Prescott C.A. \& Kendler K.S. (2003). The effects of anx iety, substance use and conduct disorders on risk of major depressive disorder. Psychological Medicine 33, 1423-1432.

Kessler R.C., Avenevoli S. \& Merikangas K.R. (2001). Mood disorders in children and adolescents: An epidemiologic perspective. Biological Psychiatry 49, 1002-1014.

Klein D.N., Lewinsohn P.M., Seeley J.R. \& Rohde P. (2001). A family study of major depressive disorder in a community sample of adolescents. Archives of General Psychiatry 58, 13-20.

Kovacs M., Devlin B., Pollock M., Richards C. \& Mukerji P. (1997). A controlled family history study of childhood-onset depressive disorder. Archives of General Psychiatry 54, 613-623.

Lewinsohn P.M., Klein D.N., Durbin E.C., Seeley J.R. \& Rohde P. (2003). Family study of subthreshold depressive symptoms: Risk factors for MDD? Journal of Affective Disorders 77, 149-157.

Mufson L., Pollack Dorta K., Wickramaratne P.J., Nomura Y., Olfson M. \& Weissman M.M. (2004). A randomized effectiveness trial of interpersonal psychotherapy for depressed adolescents. Archives of General Psychiatry 61, 577-584.

Nomura Y., Wickramaratne P.J., Warner V., Mufson L. \& Weissman M. M. (2002). Family discord, parental depression and psychopathology in offspring: 10-year follow-up Journal of the American Academy of Child and Adolescent Psychiatry 41(4), 402409.

Orvaschel H., Walsh-Allis G. \& Ye W.J. (1988). Psychopathology in children of parents with recurrent depression. Journal of Abnormal Child Psychology 16(1), 17-28.

Pine D.S., Cohen P., Gurley D., Brook J. \& Ma Y. (1998). The risk for early-adulthood anxiety and depressive disorders in adolescents with anxiety and depressive disorders. Archives of General Psychiatry 55, 56-64.

Warner V., Weissman M.M., Mufson L. \& Wickramaratne P. J. (1999).Grandparents, parents, and grandchildren at high risk for depression: A three-generation study. Journal of the American Academy of Child and Adolescent Psychiatry 38(3), 289-296. 
Weissman M.M., Gammon G.D., John K., Merikangas K.R., Warner V., Prusoff B.A. \& Sholomaskas D. (1987). Children of depressed parents: Increased psychopathology and early onset of major depression. Archives of General Psychiatry 44, 847-853,

Weissman M.M., Warner V., Wickramaratne P., Moreau D. \& Olfson M. (1997). Offspring of depressed parents. 10 Years later. Archives of General Psychiatry 54, 932-940.

Weissman M.M., Wickramaratne P.J., Adams P., Wolk S., Verdeli L. \& Olfson M. (2000). Brief screening for family psychiatric history: The family history screen (FHS). Archives of General Psychiatry $57,675-682$.

Weissman M.M., Wickramaratne P.J., Nomura Y., Warner V., Verdeli H., Pilowsky D.J., Grillon C. \& Bruder G. (2005). Families at high and low risk for depression: a 3-generation study. Archives of General Psychiatry 62, 29-36.

Wickramaratne P.J., Warner V. \& Weissman M.M. (2000). Selecting early onset probands for genetic studies: Results from a longitudinal high risk study. American Journal of Medical Genetics (Neuropsychiatric Genetics) 96, 93-101.

Wickramaratne P.J. \& Weissman M.M. (1998). Onset of psychopathology in offspring by developmental phase and parental depression. Journal of the American Academy of Child and Adolescent Psychiatry 37(9), 933-942.

Williamson D.E., Birmaher B., Axelson D.A., Ryan N.D. \& Dahl R.E. (2004). First episode of depression in children at low and high familial risk for depression. Journal of the American Academy of Child and Adolescent Psychiatry 43(3), 291-297.

Wittchen H.-U., Kessler R.C., Pfister H. \& Lieb M. (2000). Why do people with anxiety disorders become depressed? A prospectivelongitudinal community study. Acta Psychiatrica Scandinavica, Supplementum 406, 14-23. 